\title{
Students' Views of Classroom Debates as a Strategy to Enhance Critical Thinking and Oral Communication Skills
}

\author{
Asih Nurakhir ${ }^{1}$, Fiqih Nindya Palupi ${ }^{2}$, Cornelia Langeveld $^{3}$, Devi Nurmalia ${ }^{1}$ \\ ${ }^{1}$ Department of Nursing, Faculty of Medicine, Universitas Diponegoro, Indonesia \\ ${ }^{2}$ LTQ Madani Semarang, Jawa Tengah, Indonesia \\ ${ }^{3}$ Hanze University of Applied Sciences, Groningen, The Netherland \\ Corresponding Author: Asih Nurakhir (a.nurakhir@fk.undip.ac.id; a.nurakhir@gmail.com)
}

Received: 2 May 2020

Revised: 7 August 2020

Accepted: 11 August 2020

\begin{abstract}
Background: The skills in effective communication and critical thinking are essential for nurses to apply appropriate judgments in the delivery of patient care. Classroom debates are evident to be an effective strategy that can be used to improve such skills. Unfortunately, research focusing on classroom debates to promote critical thinking and oral communication skills among nursing students has not been extensively explored.

Purpose: This study aimed to explore nursing students' views of classroom debates as a learning strategy to enhance critical thinking and oral communication skills.

Methods: A descriptive qualitative research design was employed in this study. Twelve students of the undergraduate program in nursing with classroom debate experiences and willingness to participate were purposively recruited for semi-structured interviews. Open-ended questions were used, and probing questions were also generated from the participants to get more detailed information. The interviews were transcribed verbatim and analyzed using the inductive content analysis.

Results: The results of the study identified five themes, including the acquisition of new knowledge, awareness and responsiveness to diverse viewpoints and arguments, learning structuring ideas and appropriate ways of presentation, development of other necessary skills, and challenges of classroom debates in nursing education.

Conclusion: Classroom debates promoted the development of critical thinking and oral communication skills, and offered students an opportunity to develop other necessary skills in the face of today's complex healthcare. Classroom debates can be integrated into the curriculum and teaching practices of any nursing educational institutions.
\end{abstract}

Keywords: Classroom debates; critical thinking; nurse education; oral communication skill; students' views

How to Cite: Nurakhir, A., Palupi, F. N., Langeveld, C., \& Nurmalia, D. (2020). Students' views of classroom debates as a strategy to enhance critical thinking and oral communication skills. Nurse Media Journal of Nursing, 10(2), 130-145. doi:10.14710/nmjn.v10i2.29864

Permalink/DOI: https://doi.org/10.14710/nmjn.v10i2.29864 


\section{BACKGROUND}

In the face of today's complex healthcare system, all graduates of healthcare studies, including nursing, should be prepared to think critically and communicate effectively (Hall, 2011). The skills in effective communication and critical thinking are considered essential for nurses (Ralph \& Moloney, 2015) in order to apply appropriate knowledge and skilled judgments in providing care to patients (Khosravani, Manoochehri, \& Memarian, 2004). Recent changes and demands in the healthcare service also require the need for critical thinking to help healthcare workers provide excellent services (Ang, Chew, Sum, Sengupta, \& Sim, 2019). The importance of critical thinking in nursing is so evident that many educational programs evaluate their goal achievements according to the development of critical thinking (Khosravani et al., 2004).

Critical thinking is associated with a purposeful judgment that results in interpretation, analysis, evaluation, and inference (Hajrezayi, Roshani, Shahalizade, Zeynali, \& Badali, 2015). It involves a set of skills, such as analyzing, arguing, synthesizing, evaluating, and applying as well as the use of these skills to guide behaviors (Wang, Woo, \& Zhao, 2009). Critical thinking is an essential skill that affects the entire spectrum of nursing practice; the higher the critical thinking ability is, the better the nursing competence will be (Shoulders, Follett, \& Eason, 2014). The development of critical thinking has been a focus of many educators at every level of education, and becomes an essential goal of education in many societies around the world, as it promotes such disparate qualities as democracy and personal development (Larsson, 2017). Nursing faculties generally agree that students who know how to think to make better clinical judgments than those who have merely memorized facts (Khosravani et al., 2004). Therefore, nurse educators should implement new strategies to encourage active learning and enhance critical thinking skills in students.

In addition to critical thinking, effective skills in oral communication are also essential for nurses and become the heart of quality healthcare (Ralph \& Moloney, 2015). Nurses and healthcare providers should have the ability to communicate effectively, not only to patients but also to other constituents, such as doctors, pharmacists, and policymakers, to protect and advance their profession (Hall, 2011). Effective communication between nurses and patients plays a significant role in the outcome of individualized nursing care that is provided to patients (Kourkouta \& Papathanasiou, 2014), helps nurses gather information from patients, and assists patients cope with their situation, as well as to speak up in difficult situations (Bosher, 2013). The application of effective strategies of communication by nurses may reduce stress, promote wellness, and, therefore, improve the overall quality of life (Vertino, 2014).

To help students increase critical thinking and oral communication skills, nursing schools and faculties adopt various teaching strategies and innovations which actively engage students in the learning process (Popil, 2011). Active learning, in this regard, differs from passive learning as the former involves complex thinking processes and improves retention, assimilation, understanding, and appropriate application of course content (Alén, Domínguez, \& de Carlos, 2015). Through active learning strategy, it is expected that students can actively devote and engage themselves in learning process and develop necessary skills as an individual and as a team member. 
One of the active learning strategies that can be applied in nursing education is debates. Research shows that debates are a pedagogical method that can be applied to promote critical thinking and oral communication skills among students (Doody \& Condon, 2012; Hartin, Birks, Bodak, Woods, \& Hitchins, 2017). Debates foster self-directed learning, participation in a shared dialogue, and teamwork (Nisly, Kingdon, Janzen, \& Dy-Boarman, 2017). Debates allow students to develop knowledge of substantive topics and exercise skills through practice activities (Doody \& Condon, 2012; Hartin et al., 2017) and offer the participants the ability to explore a topic in more than one correct stance. Furthermore, debates promote students' use of the available evidence to support a stance and communicate a stance to other participants with differing opinions persuasively and professionally (Nisly et al., 2017), as well as increase students' active learning by giving them the responsibility to understand learning materials, which can transform their perspective from passive to active (Rodger \& Stewart-Lord, 2020). One form of debates that are conducted in the classroom are known as classroom debates.

Classroom debates are usually practiced by splitting students in a classroom into two groups; one is the pro side and the other is the con side of the topic/motion (Rodger \& Stewart-Lord, 2020). The motion can be determined by the instructors based on the materials that students learn. The two groups, which consist of two or more speakers, will speak out their arguments and oppose the opponent's arguments about the topic (Iman, 2017). The remaining students in the classroom can act as the juries, observers, or other necessary roles. Before debate practice, students are usually given time to research the topic by reading reliable papers, books, articles, and other types of resources to help them develop and organize their thoughts about the motion to produce informed arguments. When the preparation is completed, students will present the debate by delivering their arguments in turns, starting from the pro to the con sides within an allocated time. There is also a Point of Information (POI), a formal question addressed by a member of the opposing team during a debate (D'Cruz, 2003). The brainstorming sessions before the debate, the presentation of team arguments, and discussion during the debate among team members are parts of debate activities that can promote critical thinking and oral communication skills (Othman, Sahamid, Zulkefli, Hashim, \& Mohamad, 2015), as well as opportunities to challenge and rebut claims and assertions following an opponent's opening statement and main arguments (Rodger \& Stewart-Lord, 2020).

Previous studies reported positive feedbacks of classroom debates in various disciplines such as tourism (Alén et al., 2015), pharmacy (Hanna et al., 2014; Hogan \& Dunne, 2018; Toor, Smai, \& Wargo, 2017; Peasah \& Marshall, 2017), medicine (Mumtaz \& Latif, 2017; Shaw, 2012), nursing (Hartin et al., 2017; Kim \& Park, 2019), childhood studies (Brown, 2015), and Teaching English as a Second language (TESL) (Zare \& Othman, 2015; Othman et al., 2015). Alén et al. (2015) revealed that academic debates helped tourism students develop diverse and relevant learning and critical thinking through active learning. Debates gave positive effects on increased confidence and enjoyment (Toor et al., 2017), mastery of materials (Peasah \& Marshall, 2017), development of teamwork, peer assessment, communication and critical evaluation among pharmacy students (Hanna et al., 2014). In addition to critical thinking and oral communication, debates also promoted English as a Second Language (ESL) students' 
mastery of learning materials and teamwork (Zare \& Othman, 2015). In the medical context, debates gave students experience in increasing communication skills (Shaw, 2012), critical thinking, and analytical decision making (Mumtaz \& Latif, 2017), as well as confidence and leadership (Rodger \& Stewart-Lord, 2020). Debates also increased the acquisition of skills in communication, team building, and the implementation of these skills in practice among nursing students (Hartin et al., 2017).

Although literature indicated that debate is an effective strategy for improving critical thinking and communication skills among nursing students, there has been no adequate evidence from the perspective of students to support this assertion (Hartin et al., 2017). Furthermore, in recent years, few studies have focused on the results of studies conducted on classroom debates. In Indonesia, where this study took place, the evidence of the use of debates to increase critical thinking and communication skills among nursing students is scarcely found. There is a necessity to conduct a study on how nursing students viewed classroom debates in nursing education to promote critical thinking and oral communication.

\section{PURPOSE}

This study aimed to explore nursing students' views of classroom debates as a learning strategy to enhance critical thinking and oral communication skills.

\section{METHODS}

\section{Research design and participants}

The present study used a descriptive qualitative research design to explore how nursing students viewed classroom debates to enhance critical thinking and oral communication skills. Twelve undergraduate nursing students being in the second to the fourth year of their study, having classroom debate experiences, and showing a willingness to participate in the study were purposively recruited for semi-structured interviews. Openended questions were used, and probing questions were also generated from the participants to get more detailed information.

\section{Data collection}

Semi-structured interviews were conducted to get qualitative data from the participants. Participant observations and field notes were also done to support the collected data. The interviews were conducted at an agreed time between the students and the researchers at the school premises in 2019. The structured questions in this study were developed by the researchers and validated by panel judgment. The questions were focused on how students viewed classroom debates as a strategy to enhance critical thinking and oral communication skills, and whether they had benefited from debate activities. The interview was individually conducted and audio-taped with approval from the student. Each interview lasted with a duration of 30 to 40 minutes.

\section{Data analysis}

The interviews were transcribed verbatim and analyzed using the inductive content analysis summarized by Elo and Kyngas (2008). The process of analysis in this study included selecting units of analysis, making sense of the data, and learning "what is 
going on' to obtain a sense of the whole, open coding, creating categories, and abstraction.

\section{The trustworthiness of the study}

In this study, trustworthiness was achieved by four strategies, including triangulation, peer-debriefing, member checking, and appropriate interpretation (Krefting, 1991). Triangulation is the solicitation of data from multiple sources to cross-check and corroborate the evidence that sheds light on the theme. In this study, triangulation was conducted by interviews of various students with different backgrounds and the use of field notes and observations during interviews. Member checking was performed by inviting participants to provide their views and feedback on the resulted themes. Peerdebriefing was performed by the researchers to gain consensus among the researchers on data analysis. An appropriate interpretation was made by the researchers based on the collected data and relevant literature. As suggested by Creswell (2012), this study also employed an external audit in which the researchers sought an expert to review different aspects of the research to confirm the accuracy of the findings and to ensure the findings are supported by the collected data.

\section{Ethical considerations}

Administrative clearance from the head of the school where this study took place was secured before the study. A complete explanation and description of the purpose of the study, methods, potential risks, and benefits were given to all participants. The participants were also free to ask questions, refuse/accept participation in this study, and withdraw at any time without negative consequences. Informed consent was obtained from each participant before data collection. All collected data remained confidential, and access was limited only to the researchers.

\section{RESULTS}

\section{Characteristics of participants}

The participants of this study were undergraduate nursing students. The results showed that a majority of participants were females (91.67\%) and with the age of 20 to 24 years old $(M=22.20)$. A majority of the participants $(60 \%)$ had the experience of debate activities for 5-6 years that they obtained either in high schools or colleges. Most of the participants were the third-year students $(50 \%)$; the remaining were the second $(30 \%)$ and fourth-year students $(20 \%)$.

\section{Findings from the interview data}

The findings of the interviews revealed the students' views of classroom debates as a learning strategy to promote critical thinking and oral communication skills. Five general themes were developed, including the acquisition of new knowledge and ideas, awareness and responsiveness to diverse viewpoints and arguments, learning to structure ideas and appropriate ways of presentation, development of other necessary skills, and challenges of classroom debate implementation in nursing education. Some of the participants' statements were quoted below, and their identities were anonymized by a number to ensure confidentiality. 


\section{Acquisition of new knowledge and ideas}

The participants in this study reported that debates helped them develop new knowledge and ideas. Debates demanded students to engage with the subject or topic - also known as motion - during the debate preparation and presentation. All students agreed that they have to research in preparation for the debate. Once they were informed of the topic of debate, students would mostly read papers, books, articles, and other types of resources on the internet and make a summary of arguments about it, both for the pro and cons positions. Students perceived that this process assisted them develop, organize, and formulate their thoughts to produce informed arguments. Students would perform well in the debate when they have sufficient knowledge of the topic.

"We have to search and browse materials for the debate during the preparation stage. We read a lot of articles and papers which are relevant to the motion. Mostly we obtain new information or evidence that helps us construct our arguments. That really helps broaden our knowledge." (P2)

"... when we are debating, we are demanded to have the ability to think actively from the process of searching information, looking for data or evidence, developing and strengthening our arguments. We need to research the topic in order to master the topic and determine the standing point when we are faced with the position of pros or cons." (P5)

Students reported that they would be able to deliver fluent arguments and comment on or criticize the opponent's arguments only if the topic was of their mastery. In debate preparation, the information that students obtained from research and readings could be combined and summarized in such a way to form the basis of their arguments. The students' critical thinking is promoted as they have to analyze obtained information, develop counter-arguments, and respond to critical questions from their opponents. In this sense, having comprehensive knowledge and understanding of the motion would significantly contribute to the students' achievement at this level.

"We, as debaters, are required to provide the best solution of the motion given so that we need to prepare materials and arguments that are rational, specific, and can counter the opponent's opinions. Personally, when I master the topic, I find it easier to criticize and counter opposing arguments" (P1)

"If you are participating in a debate, you will be assigned a certain topic. Sometimes the topic is beyond your expectation, and therefore you need to read a lot, especially when the topics are not familiar. If you read a lot, you know a lot (about the topic), and so you will be able to give your views or ideas fluently to counter the opposing arguments." (P10)

\section{Awareness and responsiveness to diverse viewpoints and arguments}

This theme describes how debates assisted students consider great varieties or diverse viewpoints and arguments that they found in the literature. Before a debate presentation, students would usually be given time to explore the topic as an individual speaker or a team member. Whether they were to be in the pro or cons side was not determined before a debate practice, and therefore, students had to explore both pro and con sides of the motion. This exploration would encourage students to engage with numerous ideas 
and arguments in the literature. They learned to be aware and alert that there are a lot of possible arguments that could strengthen or weaken a particular position. They learned to anticipate and predict what would be going on in the debate with those sorts of arguments. Awareness of diverse viewpoints and arguments are guaranteed.

“... In debates, we are faced with different opinions or dealing with people who have different arguments. So we learn to consider these differences. When we are preparing the debate, we also find a lot of information and evidence that can be used to defend or attack our position. So, debates teach us to develop an understanding of different perspectives." (P5)

"In practicing debates, a debater should be able to see diverse viewpoints. Every debater has different arguments as a result of research that they conducted, and so does the opposing team. They have arguments that will be different from ours. So, what we need to do is to have broad knowledge and anticipate all possibilities to produce strong arguments" (P11).

In a debate presentation, students also learn to be critical thinkers and presenters by being responsive and alert to the opponent's attacking arguments. They need to analyze and think fast to respond to any opposing arguments. In order to do so, students need to think critically with the support of data they had gained before the debate. Furthermore, they need to pay attention to detailed information that can be their counter-arguments or POIs for the opponents.

"... there is a reciprocal interaction between debate teams, the pro, and the cons. We have to carefully listen to the opponent's arguments and quickly make a POI (point of interruption) when something is missing or going wrong. It is a quick process. We have to comprehend information, opposing arguments and strengthen our arguments" (P6)

"In a debate, students must be able to think fast, even in conditions where the arguments are not by their own beliefs. Nevertheless, they must convince the judges, especially when we have to respond and attack the arguments of the opposing team." (P3).

"In a debate, we should not argue based on our assumptions, but on evidence. We must defend our arguments with our best effort. In this case, we have to be skillful in analyzing the situation and providing credible information to oppose the other team." (P9)

\section{Learning structuring ideas and appropriate ways of presentation}

This theme describes students' views on how classroom debates promoted learning of structuring ideas and appropriate ways of presentation, affecting increased skills of critical thinking and communication. Students perceived that debates pushed them to keep the original problem in mind, stick to the point, and provide a clear explanation or elaboration with specific details. That meant students had to arrange their arguments in such a systematic way that is easy to follow and understand, not only to the opponents but also to judges and audience. 
"In debates, there is a time limit for speaking or presenting arguments. For example, a first speaker/debater may be given 7 minutes. In this case, the debater needs to arrange the sentences of his arguments so that they are easy to understand and have clear points. In debates, we are not just talking fast, but there must also be an emphasis on points that are considered important. This trains my speaking ability." (P1)

"I also learn how to speak appropriately so that the idea of my speech is accepted and understood by the people who are listening." (P5)

The participants in this study also believed that debates trained their brains to systematic thinking and mind and control of their body language, voice, and eye contact. To ensure the audience of their presented arguments, the students should speak dynamically with precise intonation and articulation, as well as suitable pauses and emphasis. They should know when they have to speak fast or slowly, and it is all depending on their purpose and debate circumstances.

"Debates also train the brain to think systematically, which means looking at a topic from various points of view in order to produce the right output. Debates also improve communication skills because, in debates, a person can learn to communicate thoughts in a coherent and detailed form so that the recipient of the message understands the rationale of what is communicated." (P10).

"The way we speak, the pace, intonation, articulation, gesture, and eye contacts are certainly needed to help convince the jury or audience. I believe debates help me a lot to achieve those things." (P2)

\section{Development of other necessary skills}

The participants also reported that classroom debates promoted the development of other necessary soft skills in support of critical thinking and oral communication. Most students reported debates helped them increase confidence, and learn to appreciate others even if they were in the opposite position.

"Yes, I felt really nervous and hesitant to do a debate for the first time. After some practice, I felt that my confidence develops." (P2)

"Yes, debates help us learn how to respect and appreciate other people's arguments." (P4)

"In a debate, we mostly disagree with the opponent's arguments, but we have to keep in mind that these opposing arguments should be appreciated." (P8)

"This debate teaches me how to respect other people and opinions, and even they are in opposition with us." (P3)

The students also stated they usually cooperated with their teammates to discuss and construct arguments for their team. In the preparation stage, they commented on each other drafts of arguments to seek the best ones. During the debate, students also worked together to criticize the opponent and defend their arguments, as well as showed signals when allocated time for a speech was over. 
"Debates also promote teamwork because when we are in a debate team, we need to communicate with each other as team members for what to prepare in the presentation. It is important so that the team has coherent arguments." (12)

"Debates increased my skills in collaborating with others." (P5)

"This activity (debate) teaches me how to work with other members of the team, for example, during case-building (preparation) or presentation of the arguments." (P1)

\section{Challenges of classroom debates in nursing education}

The participants reported that although classroom debates could promote critical thinking and oral communication skills, there were challenging issues when debates are implemented as a learning strategy. A majority of students perceived that debate technicality and preparation time were some issues that should be taken into account in implementing classroom debates. To practice a good debate, students should understand debate technicality and rules so that they know and understand their duties as a team member. Understanding debate technicality was deemed essential for the students to demonstrate quality debate. Some students also mentioned that they needed more time in preparation so that they had more opportunities to structure arguments, and therefore, their presentation could be easily understood by the audiences.

"I think one of the issues in implementing classroom debates is the preparation time. When I practiced debates with my team, we need a long time for preparation (case-building). Sometimes, we are given thirty minutes, but we think it is not enough. We are not yet done with structuring the arguments, but the time is running out." (P3)

"The preparation time should be considered. We cannot prepare our arguments well if the time is limited. So in the past, my teachers gave the topic of the debate in advance before we practiced it" (P5)

"I think, when we want to use debates in the classroom, we have to ensure that all students are familiar with that. If not, they may not be able to follow the activity well. So students need to be exposed to the rules and technicality of debates, and that is important for teachers." (P7)

Another issue of classroom debate was related to motions. Some students mentioned that sometimes they were faced with such a problematic motion to debate. They argued that the motions should be adjusted to their level of knowledge; it should not be too easy or complicated and should be well formulated in accordance to debate rules.

"Sometimes, I find it difficult to understand the motion; it can be because of my capacity, or the topic is just too difficult for me." (P8)

"The motion should be adjusted to the level of our knowledge. Before the debate begins, it should be ensured that all students share the same perception of the topic. Otherwise, they will have difficult times and will not be able to perform optimally in the debate." (P3) 
In general, the results of interviews illustrate that the students in this study consistently perceived the benefits of classroom debates to enhance critical thinking and oral communication skills mostly.

\section{DISCUSSION}

The present study aimed to explore how nursing students viewed classroom debates as a learning strategy to enhance critical thinking and oral communication skills. Results from qualitative findings showed that the students positively perceived classroom debates concerning their increased critical thinking and oral communication skills. Not only that, but students also believed that classroom debates promoted teamwork skills, confidence, respect to others, and other essential attributes for nurses.

The finding of this study showed that debates help students develop new knowledge and ideas, leading to the promotion of critical thinking and oral communication skills. This finding confirms some of the previous studies on debates (Aclan \& Aziz, 2015; Iman, 2017; Peasah \& Marshall, 2017; Rodger \& Stewart-Lord, 2020; Scott, 2008). Debates demand students to engage with the topics as they have to research debate preparation. Students would mostly read reliable papers, journals, or reports for their references. This process helps students develop and formulate their thoughts about the motion to produce informed arguments. In preparation, the information that students obtain from research and reading could be combined and summarized in such a way to form the basis of their arguments. The skill of critical thinking is, therefore, promoted as they have to analyze the obtained information and develop counter-arguments to their opponents (Rodger \& Stewart-Lord, 2020). Having brainstorming and discussion sessions of newly gained knowledge among group members during preparation before a debate activity was evident to encourage the development of critical thinking among students (Mumtaz \& Latif, 2017; Othman et al., 2015). Furthermore, the acquisition of new knowledge and ideas will also affect students' oral communication skills as they would be able to deliver fluent arguments and comment on or criticize the opponent's arguments only if the topic is of their mastery. Students would perform well in the debate when they have sufficient knowledge of the topic.

Classroom debates were also evident in this study to promote students' awareness and responsiveness to diverse viewpoints and arguments that affect their ability to think. It is congruent with a majority of previous studies (Brown, 2015; Hanna et al., 2014; Khosravani et al., 2004; Mumtaz \& Latif, 2017; Zare \& Othman, 2015), reporting that students involved in debates would learn to consider and understand different perspectives, learn to use evidence to support arguments and viewpoints, as well as be open-minded and accept reasonable criticisms which are keys to critical thinking (Zare \& Othman, 2015). Before a debate presentation, students would usually be given time to explore the topic/motion for both its pros and cons sides. This exploration encourages students to engage with numerous ideas and arguments in the literature. They can learn to anticipate and predict what will be going on in the debate if those sorts of arguments are employed. Through debates, students also learn to examine issues in-depth, consider contrasting viewpoints, and defend a position that leads to critical thinking (Alén et al., 2015). Debate activities also allow students to identify an issue that should be resolved and demonstrate a comprehensive analysis of the issue, including appraisal, critique, 
and reasoning of the issue for potential solution. Such skills are important as healthcare professionals are frequently faced with new evidence, and the only way to distinguish the valid from the invalid is to appraise and critique the evidence (Hall, 2011). Debates promote critical thinking as these activities require the students to synthesize, analyze, and evaluate arguments (Zare \& Othman, 2015). In debates, students are encouraged to interact and be involved in the selected topics, enabling students to recognize that the debate is an exploration of issues relevant to their professional role (Hartin et al., 2017).

This study also showed that critical thinking and oral communication were promoted through classroom debates where the students learned to develop structured ideas and appropriate attributes of presentation, such as voice, gesture, and eye contact. Debates make students learn to arrange arguments in such a way that is easy to follow and understand, not only to their peers and opponents but also to judges and audience. As reported in previous research, students have to use evidence and consider viewpoints to support their arguments in a well-organized and persuasive manner, as well as in responding to the opposition (Koklanaris et al., 2008). To present structured arguments, students need extensive research to formulate convincing arguments and substantiate them with evidence (Ang et al., 2019). Through such activities, the students' critical thinking is promoted. The skill of oral communication in this study is promoted by debates as reported in some previous studies (Hall, 2011; Hartin, 2017; Mumtaz \& Latif, 2017; Nisly et al., 2017; Shaw, 2012; Zare \& Othman, 2015). The skill of effective communication represents the heart of quality healthcare (Ralph \& Moloney, 2015), affecting the success of the outcome of nursing care for patients (Kourkouta \& Papathanasiou, 2014). In debates, students are required to use verbal communication to convince the audience and adjudicators using a well-planned analysis of the arguments that support and refute their point of views (Shaw, 2012) and control of body language, speech, and eye contacts in the delivery of arguments (D'Cruz, 2003). Students also have opportunities to articulate their thoughts based on evidence (Mumtaz \& Latif, 2017) and rebut the opponent's arguments. Furthermore, the students should also defend their points of view and directly respond to the questions that they are asked (Alén et al., 2015). Debates demand students to communicate their argument in a persuasive manner (Dy-Boarmana, Nisly, \& Costello, 2018; Kim \& Park, 2019). Such situations require the students to have confidence to talk in front of the public, and debates promote students' confidence to alleviate their fear of speaking in front of people (Zare \& Othman, 2015).

The result of this study also showed that classroom debates promoted the development of other necessary skills in support of critical thinking and oral communication, such as confidence, teamwork, and appreciation or respect to others. A study by Mumtaz and Latif (2017) reported that debates increased skills of tolerance towards diverse ideas and respecting others' opinions. The sense of respect within the students develops as the students are faced with several opposing arguments from the opponent's team. Debates allow the students not only to know that an issue needs to be solved, but also to show a more in-depth analysis of the issue, including appraisal, critique, and reasoning for a potential solution (Hall, 2011). In debate presentation, debaters have to talk to and work with each other to make sure that their ideas are coherent. Thus, the skill of teamwork is promoted. If they lack this critical skill, they might have incoherent arguments during debates (Aclan \& Aziz, 2015). Debates also encourage students to support each other as 
team members to raise confidence. The confidence that indicates the ability to present oneself and ideas appropriately is promoted as students participating in debates have to do many things they may not do in a common discussion. Students will need to be able to think critically about issues to present relevant arguments. They also need to have the ability to express thoughts in a way that is understood by audience (Pulver, 2018).

A classroom debate is an interesting learning strategy that can engage students in an active teaching and learning process. However, some challenging issues or problems in its implementation might be encountered as found in this study. A majority of students perceived that debate technicality, preparation time, and motion selection were examples of issues that should be taken into account in classroom debates. Similar challenges are also reported in a study by Zare and Othman (2015). To demonstrate a good debate, students should understand its technicality and rules so that they know their duties as a team member and understand what and how they have to speak the arguments. Understanding debate technicality is important for students to demonstrate quality debate. Similarly, motions of debates should also be adjusted to students' level of knowledge; they should not be too easy or too complicated and should be formulated (D'Cruz, 2003). The topic of debate affects how students are involved in debates. As a teaching method, debates allow students to practice and cultivate communication and skills in solving problems that assist the achievement of competencies. Therefore, regardless of potential challenging issues in debates, teachers at educational institutions should consider this as a potential teaching strategy (McGeea, Pius, \& Mukherjee, 2020).

Considering the results of this study, it is believed that classroom debates offer the students a valuable opportunity to develop critical thinking and oral communication abilities, as well as other necessary skills to face today's healthcare system. Critical thinking is associated with nurse performance (Suangga \& Tuppal, 2017). Previous research reported that problem-based learning was the strategy that is mostly used to promote critical thinking in an undergraduate nursing course (Carvalho et al., 2017) and encourage students as self-directed learners (Kong, Qin, Zhou, Moub, \& Gao, 2014). As critical and analytic skills are not naturally present in college students, it is necessary to involve higher-order thinking activities, such as debates, to instill these skills (Yang \& Rusli, 2012). Debates can be used as an alternative to teaching and learning strategies and incorporated into the course curriculum. Furthermore, debates are scalable that they can be used without restriction to the mode of delivery, such as in face-to-face, online, or blended courses (Park, Kier, \& Jugdev, 2011). Debates can also be integrated with other active learning strategies such as problem-based learning, mind mapping, and collaborative learning.

\section{CONCLUSION}

This study revealed the positive views of nursing students towards classroom debates. The students perceived that classroom debates mostly enhanced their critical thinking and oral communication skills. Classroom debates also offered the students a valuable opportunity to develop other necessary skills for nursing students in the face of today's complex healthcare system, such as confidence, teamwork skills, and respect for others. Debate rules and technicalities, preparation time, and motion selection are challenging 
issues in the implementation of classroom debates in nursing education that should be taken into account by nurse educators.

Considering the results of the study, it is recommended that in order to prepare nursing graduates with effective communication and critical thinking skills, the schools should consider and incorporate the use of classroom debates in their curriculum and teaching practices. Evidence on the use of classroom debates among nursing students is scarcely found, and therefore, this study might be a valuable reference for any nursing schools to increase their teaching practices. Further research using a quantitative approach may be conducted to investigate the effects of classroom debates on nursing students' technical and non-technical skills.

\section{ACKNOWLEDGMENT}

The researchers would like to thank the students for their voluntary participation in this study, and Prof. Rozano C. Locsin, a visiting professor at Diponegoro University, for his feedback in writing this paper.

\section{CONFLICT OF INTEREST}

The authors declare no conflict of interest.

\section{REFERENCES}

Aclan, E. M., \& Aziz, N. H. A. (2015). Exploring parliamentary debate as a pedagogical tool to develop English communication skills in EFL/ESL classrooms. International Journal of Applied Linguistics \& English Literature, 4(2),1-16. doi:10.7575/aiac.ijalel.v.4n.2p.1

Alén, E., Domínguez, T., \& de Carlos, P. (2015). University students' perceptions of the use of academic debates as a teaching methodology. Journal of Hospitality, Leisure, Sport \& Tourism Education, 16, 15-21. doi:10.1016/j.jhlste.2014.11.001

Ang, R. X., Chew, Q.H., Sum, M. Y., Sengupta, S., \& Sim, K. (2019). Systematic review of the use of debates in health professions education - does it work?. GMS Journal for Medical Education, 36(4), 37. doi:10.3205/zma001245

Bosher., S. (2013). English for nursing. In B. Paltridge \& S Starfield. (eds). The handbook of English for specific purposes (pp. 263-282). West Sussex: WileyBlackwell.

Brown, Z. (2015). The use of in-class debates as a teaching strategy in increasing students' critical thinking and collaborative learning skills in higher education. Educational Futures, 7(1), 39-55.

Carvalho, D. P. S. R. P., Azevedo, I. C., Cruz, G. K. P., Mafra, G. A. C., Rego, A. L. C, Vitor, A. F., ... \& Junior, M. A. F. (2017). Strategies used for the promotion of critical thinking in nursing undergraduate education: A systematic review. Nurse Education Today, 57, 103-107. doi:10.1016/j.nedt.2017.07.010

Creswell, J. W. (2012). Educational research: Planning, conducting and evaluating quantitative and qualitative research. Boston, MA: Pearson.

D’Cruz, R. (2003). Australia-Asia Debating Guide (2 ${ }^{\text {nd }}$ ed.). Victoria: Australian Debating Federation 
Doody, O., \& Condon, M. (2012). Increasing student involvement and learning through using debate as an assessment. Nurse Education in Practice, 12, 232-237. doi:10.1016/j.nepr.2012.03.002

Dy-Boarmana, E. A., Nisly, S. A, \& Costello, T. J. (2018). It's no debate, debates are great. Currents in Pharmacy Teaching and Learning, 10, 10-13. doi:10.1016/j.cptl.2017.09.016

Elo, S., \& Kyngas, H. (2008). The qualitative content analysis process. Journal of Advanced Nursing, 62, 107-115. doi:10.1111/j.1365-2648.2007.04569.x

Hajrezayi, B., Roshani, A. H., Shahalizade, M., Zeynali, M., \& Badali, M. (2015). Effectiveness of blended learning on critical thinking skills of nursing students. Journal of Nursing Education, 4(1), 49-59.

Hall, D. (2011). Debate: Innovative teaching to enhance critical thinking and communication skills in healthcare professionals. The Internet Journal of Allied Health Sciences and Practice, 9(3), 1-8.

Hanna, L-A., Barry, J., Donnelly, R., Hughes, F., Jones, D., Laverty, G., ... \& Ryan, C. (2014). Instructional design and assessment. Using debate to teach pharmacy students about ethical issues. American Journal of Pharmaceutical Education, 78(3), Article 57. doi:10.5688/ajpe78357.

Hartin, P., Birks, M., Bodak, M., Woods, C., \& Hitchins, M. (2017). A debate about the merits of debate in nurse education. Nurse Education in Practice, 26, 118-120. doi:10.1016/j.nepr.2017.08.005

Hogan, S., \& Dunne, J. (2018). Evaluating the effectiveness of a focused debate on the development of ethical reasoning skills in pharmacy technician students. American Journal of Pharmaceutical Education, 82(6), Article 6280. doi:10.5688/ajpe6280

Iman, J. N. (2017). Debate instruction in EFL classroom: Impacts on the critical thinking and speaking skills. International Journal of Instruction, 10(4), 87-108. doi:10.12973/iji.2017.1046a

Khosravani, S., Manoochehri, H., \& Memarian, R. (2004). Developing critical thinking skills in nursing students by group dynamics. The Internet Journal of Advanced Nursing Practice, 7(2), 1-9.

Kim, W-J., \& Park, J-H. (2019). The effects of debate-based ethics education on the moral sensitivity and judgment of nursing students: A quasi-experimental study. Nurse Education Today, 83, 104200. doi:10.1016/j.nedt.2019.08.018

Koklanaris, N., Mackenzie, A. P., Fino, M. E., Arslan, A. A., \& Seubert, D. E. (2008). Debate preparation/participation: An active, effective learning tool. Teaching and Learning in Medicine, 20(3), 235-238. doi:10.1080/10401330802199534.

Kong, L. N, Qin, B., Zhou, Y. Q., Moub, S. Y., \& Gao, H. M. (2014). The effectiveness of problem-based learning on development of nursing students' critical thinking: A systematic review and meta-analysis. International Journal of Nursing Studies, 51, 458-469. doi:10.1016/j.ijnurstu.2013.06.009

Kourkouta, L., \& Papathanasiou, I. V. (2014). Communication in nursing practice. Mater Sociomed, 26(1): 65-67. doi:10.5455/msm.2014.26.65-67

Krefting, L. (1991). Rigor in qualitative research: The assessment of trustworthiness. The American Journal of Occupational Therapy, 45(3), 214-222. doi:10.5014/ajot.45.3.214. 
Larsson, K. (2017). Understanding and teaching critical thinking - A new approach. International Journal of Educational Research, 84, 32-42. doi:10.1016/j.ijer.2017.05.004

McGeea, E.U., Pius, M., \& Mukherjee, K. (2020). Assessment of structured classroom debate to teach an antimicrobial stewardship elective course. Currents in Pharmacy Teaching and Learning, 12, 220-227. doi:10.1016/j.cpt1.2019.11.016

Mumtaz, S., \& Latif, R. (2017). Learning through debate during problem-based learning: An active learning strategy. Advances in Physiology Education, 41, 390394. doi:10.1152/advan.00157.2016

Nisly, S. A., Kingdon, L. K., Janzen, K. M., \& Dy-Boarman, E. A. (2017). Using debates to mimic clinical discussion in experiential education. Innovations in Pharmacy, 8(4), Article 9.

Othman, M., Sahamid, H., Zulkefli, M. H., Hashim, R., Mohamad, F. (2015). The effects of debate competition on critical thinking among Malaysian second language learners. Middle-East Journal of Scientific Research, 23(4), 656-664. doi:10.5829/idosi.mejsr.2015.23.04.22001

Park, C., Kier, C., \& Jugdev, K. (2011). Debate as a teaching strategy in online education: A case study. Canadian Journal of Learning and Technology, 37(3), 117. doi:10.21432/T2FW2R

Peasah, S. K., \& Marshal, L. L. (2017). The use of debates as an active learning tool in a college of pharmacy healthcare delivery course. Currents in Pharmacy Teaching and Learning, 9, 433-440. doi:10.1016/j.cptl.2017.01.012

Popil, I. (2011). Promotion of critical thinking by using case studies as teaching method. Nurse Education Today, 31, 204-207. doi:10.1016/j.nedt.2010.06.002

Pulver, T. (2018). Build your students' confidence and self-esteem through debate. Retrieved from https://www.competitionsciences.org/2018/05/14/build-yourstudents-confidence-and-self-esteem-through-debate/.

Ralph, N., \& Moloney, C. (2015). Safety and quality in clinical communication. In Birks M., Davis J., Chapman Y (Eds.). Professional and therapeutic communication. Melbourne: Oxford University Press.

Rodger, D., \& Stewart-Lord, A. (2020). Students' perceptions of debating as a learning strategy: A qualitative study. Nurse Education in Practice, 42, 102681. doi:10.1016/j.nepr.2019.102681

Scott, S. (2008). Perceptions of students' learning critical thinking through debate in a technology classroom: A case study. The Journal of Technology Studies, 34(1), 3944. doi:10.21061/jots.v34i1.a.5

Shaw, J. A. (2012). Using small group debates to actively engage students in an introductory microbiology course. Journal of Microbiology \& Biology Education, 13(2), 155-160. doi:10.1128/jmbe.v13i2.420

Shoulders, B., Follett, C., \& Eason, J. (2014). Enhancing critical thinking in clinical practice. Implications for critical and acute care nurses. Dimensions of Critical Care Nursing, 33(4), 207-214. doi:10.1097/DCC.0000000000000053

Suangga, F., \& Tuppal, C. P. (2017). Motivation among Indonesian nurses in pursuing continuing professional education and its relationship to their competencies. Nurse Media Journal of Nursing, 7(1), 24-34. doi:10.14710/nmjn.v7i1.15125 
Toor, R., Samaib, K., \& Wargo, R. (2017). Debate as an alternative method for medical literature evaluation. Currents in Pharmacy Teaching and Learning, 9, 427-432. doi:10.1016/j.cptl.2017.01.009

Vertino, K. (2014). Effective interpersonal communication: A practical guide to improve your life. OJIN: The Online Journal of Issues in Nursing, 19(3), Manuscript 1. doi:10.3912/OJIN.Vol19No03Man01

Wang, Q., Woo, H., \& Zhao, J. (2009). Investigating critical thinking and knowledge construction in an interactive learning environment. Interactive Learning Environment, 17(1), 95-104. doi:10.1080/10494820701706320

Yang, C-H., \& Rusli, E. (2012). Using debate as a pedagogical tool in enhancing preservice teachers learning and critical thinking. Journal of International Education Research, 8(2), 135-144. doi:10.19030/jier.v8i2.6833

Zare, P., \& Othman, M. (2015). Students' perceptions toward using classroom debate to develop critical thinking and oral communication ability. Asian Social Science, 11(9), 158-170. doi:10.5539/ass.v11n9p158 